\title{
ESTUDIOS
}

\section{EXPLICACIONES MITOLÓGICAS SOBRE EL ORIGEN DE LA ESCRITURA CHINA}

\section{MYTHOLOGICAL EXPLANATIONS ABOUT THE ORIGIN OF CHINESE WRITING}

\author{
Gonzalo Miranda Márquez ${ }^{1}$ \\ Universidad de Sevilla (España)
}

Resumen: El origen de la escritura china sigue siendo a día de hoy una cuestión que no deja de despertar gran interés. Con el presente trabajo pretendemos exponer ciertos aspectos de dicha escritura, centrando la investigación en sus orígenes y prestando una especial atención a las explicaciones mitológicas que se han dado al respecto. Se exponen cuatro personajes destacados de la mitología china en torno a los cuales se han centrado los mitos sobre el inicio de esta escritura milenaria. chinos.

Palabras clave: mito, mitología, escritura china, caracteres

Abstract: The origin of the Chinese writing is still a matter of great interest nowadays. In the present work we intend to expose certain aspects of this writing system, focusing our research on its origins and paying special attention to the mythological explanations that have been given in this regard. Four major characters of the Chinese mythology are exposed, around which myths about the beginning of this millenary writing have been focused on.

Keywords: myth, mythology, Chinese writing, Chinese characters

[1] Profesor Asociado en la Universidad de Sevilla. 


\section{Introducción}

Los mitos han acompañado a las personas desde los albores de la humanidad. Todas las civilizaciones los han tenido y transmitido oralmente de una generación a otra desde tiempos inmemoriales. Son uno de los elementos estructurales de la cultura, ya que en cierta manera esta se nutre de ellos, mediante la cohesión de pensamiento que proporcionan a todos los integrantes del grupo. Así, compartir mitos es compartir un mismo modo de pensamiento y, por tanto, una forma de actuar; acompañan a las personas y son susceptibles de cambio o reinterpretación según evolucione su manera de pensar. Con el tiempo y el desarrollo de las sociedades, muchos fueron desapareciendo, otros fueron quedando recogidos por escrito y llegan hasta nuestros días. Algunos de ellos todavía se mantienen vivos y, dada la faceta imaginativa del ser humano - y el carácter de los mitos, que se nutren de la imaginación en lugar de la razón-, no podemos descartar la posibilidad de que en el futuro haya culturas donde continúen surgiendo otros nuevos.

El nacimiento del mito suele generalmente asociarse a la necesidad etiológica del ser humano, es decir, a un intento de explicar su origen, el del universo, y la relación que hay entre ambos. Ya Lewis Spence, a principios del siglo pasado, definió la mitología como la forma mediante la que los salvajes explican el mundo en el que viven (Spence, 2000: 23).

Muchos mitos han dado lugar a adoraciones y cultos, y ello parece estar en cierto modo relacionado con la necesidad intrínseca a las personas de controlar su entorno. La arbitrariedad y el azar generan una incertidumbre en ellas que va contra su propia naturaleza. Los seres humanos parecen estar programados genéticamente para buscar la supervivencia propia y de sus sucesores-. El no poder tener la certeza, por ejemplo, de si la caza de la mañana siguiente será exitosa, si la cosecha de la temporada será abundante, o si habrá grandes sequías o inundaciones que provoquen catástrofes, conlleva inseguridad sobre el sustento y la supervivencia. Por eso, muchos de los mitos ancestrales versan sobre el poder que ejercen seres divinos o sobrenaturales sobre el entorno humano. Los rituales y ceremonias realizadas en honor a ellos pretenden lograr transmitir tranquilidad a las personas sobre todo aquello que escapa a su control, porque no depende de ellas. Así, han surgido mitos sobre seres divinos (que hayan creado el mundo, que puedan destruirlo, y que protejan a las personas de posibles adversidades o los castiguen con desastres naturales y calamidades si desatan su furia), también los hay de carácter animista en torno al clima (imprescindible para poder obtener buenas cosechas que garanticen 
alimentos), el cielo, los astros y los fenómenos atmosféricos (responsables de tormentas y sequías), etc.

De modo que los mitos no tratan cuestiones insignificantes y, si lo hacen, lo más probable es que no consigan perdurar. Versan más bien sobre cuestiones que son -o que en algún momento fueron-de importancia para las personas. Y tal es la índole que tiene la escritura china en el gigante asiático, goza de un estatus muy elevado y desde sus orígenes hasta ahora ha sido y es de suma importancia, porque para los chinos sus grafías - o caracteres, como comúnmente han sido denominados en Occidente-, representan muchísimo más que una simple forma de escribir; podemos afirmar que, dado el carácter oracular con que eran utilizadas originalmente, fueron una forma de conexión con las deidades, y hoy día sin duda son, entre otras cosas, símbolo de identidad, motivo de orgullo y muestra de la excelencia de su vasta cultura. Resulta natural que, siendo esto así, existan diversas explicaciones mitológicas que expliquen su origen.

\section{La escritura china}

Con un legado milenario, es la más antigua de las escrituras que se continúan utilizando en la actualidad. Hay que ser conscientes, no obstante, de que la actual difiere en gran medida de la que se utilizaba hace miles de años, sin embargo conserva algunas características que hacen que el sistema de antaño y el de hoy no se consideren dos distintos, sino la evolución y desarrollo natural de uno solo, entre otras, por las siguientes razones:

A diferencia de la mayoría de sistemas de escritura, la evolución del chino no terminó desembocando en la fonografía, porque, a pesar de que al analizar las partes que componen las grafías chinas usadas en la actualidad, se puede apreciar que en la gran mayoría de los casos -el 85\% aproximadamente- hay componentes tanto semánticos, como fonéticos, cuando se incorporaron los componentes fonéticos, fueron extraídos del abanico de grafías ya existentes, de modo que las resultantes se presentaban a ojos del lector como una nueva unidad indivisible (Folch Fornesa, 2002: 95-98). De modo que no existen hoy día reglas mediante las cuales podamos conocer con exactitud su pronunciación al primer golpe de vista $y$, por ende, la escritura china dista mucho de los sistemas fonográficos.

A día de hoy no solo se mantienen en vigor muchas de las milenarias grafías primigenias con fuerte carácter pictográfico, sino que un gran 
número de ellas siguen formando parte de la escritura actual con una amplia frecuencia de uso.

La tercera peculiaridad digna de mención es que, desde sus orígenes hasta hoy, cada grafía conlleva un significado por sí misma, lo que provoca que dicha escritura sea un filtro para todas las ideas y doctrinas externas que pretenden penetrar en el país (Folch Fornesa, 2002: 106107), puesto que cualquier nuevo concepto externo al traducirlo a la lengua china se impregna inevitablemente con los sentidos intrínsecos que conlleven las grafías usadas para su traducción.

Además de todo lo expuesto, también es importante resaltar su profunda dimensión artística. François Cheng, entre otros pensadores, es partícipe de la idea de que poesía y pintura mantienen una estrecha relación, que queda reflejada en la tradición de caligrafiar versos en el espacio en blanco de una pintura (Cheng, 2007: 24) Esto es debido a que el origen de la escritura está fuertemente vinculado a la pictografía, de modo que los caracteres chinos transmiten una gran variedad de sentidos visuales, lo que hace que estén íntimamente relacionados con la pintura. Por todo esto, la caligrafía puede ser considerada como la más elevada forma de expresión artística, en tanto que une y armoniza a la perfección la escritura con la pintura, y ambas con la filosofía.

Estos son solo algunos de los motivos que hacen que para los chinos su escritura tenga tanta relevancia. No es raro oírlos vanagloriarse de ella, de su antigüedad, de las dificultades que conlleva su aprendizaje y de las peculiaridades que la distinguen de otros sistemas, porque, en cierto modo, eso es reafirmar el esplendor y grandeza milenaria de su civilización, su genialidad y talento extraordinario, así como la identidad propiamente china respecto a las demás culturas.

\section{El origen de la escritura china}

A pesar de las múltiples investigaciones e innumerables hallazgos arqueológicos, no hay consenso sobre la antigüedad de la escritura china, no obstante, según descubrimientos recientes, las primeras pictografías podrían llegar a tener en torno a cinco mil años. Sin embargo, es difícil - por no decir imposible a día de hoy- poder confirmar que exista una relación directa entre ellas y las usadas en la actualidad. Existe la opinión de que esas grafías primigenias no se combinaban entre sí para formar textos y, por consiguiente, no se pueden considerar un sistema de escritura (Rovira Esteva, 2010: 28). Además hay investigadores que sostienen que 
esas pictografías originarias no eran más que símbolos gráficos, y una grafía solamente puede considerarse escritura cuando se encuentra asociada a un sonido convencional de la lengua hablada (Folch Fornesa, 2002: 93). No obstante, hay que considerar la posibilidad de que esas primeras pictografías pudieran ser el germen de lo que posteriormente derivaría en la escritura china.

Por estas razones, su origen es un tema que continúa abierto y sigue siendo una cuestión de actualidad entre los sinólogos. Por el momento no se han encontrado evidencias que demuestren que los pictogramas originarios pudieran dar lugar a un sistema de escritura. Lo que sí se sabe con seguridad es que la escritura de la dinastía 商 Shāng (1600-1046 a.n.e.) -usada según los descubrimientos arqueológicos en torno al año 1200 a.n.e.- conformaba ya un sistema totalmente desarrollado, y que hay una relación clara y directa entre la de entonces y la actual, por lo que es posible afirmar, sin temor a equivocarnos, que la escritura china cuenta ya con más de tres mil años de antigüedad.

Hay quienes han defendido que la escritura china puede proceder de Mesopotamia, sin embargo, las similitudes entre la escritura cuneiforme y la china no van más allá del origen pictográfico que ambas comparten, por lo que por el momento esta teoría carece de pruebas arqueológicas que la respalden (Ramírez Bellerín, 2004: 66). Si tomamos los hallazgos del siglo XIII a.n.e. como su comienzo, hemos de admitir que la china es muy posterior a la cuneiforme y no se podrían descartar con total seguridad influencias extranjeras que hubieran llegado de Asia Central, no obstante, el sistema de escritura chino se adecúa perfectamente al fuerte carácter monosilábico de su lengua. Esta idoneidad entre lenguas escrita y hablada es un valioso argumento en favor de que el origen de la escritura china es autóctono (Alleton, 2009: 74). En cualquier caso, a pesar de que las cuestiones en torno su inicio están aún abiertas a debate, no existe ninguna evidencia que le otorgue una procedencia extranjera, ni existe una sola grafía de escrituras sumeria o egipcia que se encuentre entre las grafías primigenias chinas (Martínez Robles, 2007: 122), por lo que a día de hoy no es posible establecer entre ellas una relación histórica demostrable. De modo que, siendo esto así, no es de extrañar que todos los mitos sobre la creación de la escritura china partan de la idea de que esta tuvo un origen autóctono. 


\section{Explicaciones mitológicas sobre el origen de la escritura china}

China cuenta con una extensa mitología, pero, como señala Goepper, difiere respecto a la de otros pueblos. El hombre primitivo exterioriza su forma de ser y sus problemas, atribuyendo a sus divinidades sus propias características, así sus dioses y otros seres mitológicos suelen estar en constante conflicto entre ellos o con otros seres, y se comportan de manera inmoral, igual que lo hace el mismo hombre salvaje (Spence, 2000: 21). Sin embargo, en los mitos, leyendas y relatos chinos predominan personajes que llevan a cabo grandes hazañas civilizadoras (Goepper, 1988: 47). Así pues, se tratan temas muy diversos como son, entre otros, las incógnitas de la naturaleza, el origen del mundo, de la humanidad, de la agricultura, de la medicina, la organización del matrimonio y la familia, el descubrimiento de la caza y la pesca, la aparición de la ciencia matemática, los intentos del ser humano por controlar los fenómenos naturales, y por supuesto, como ya hemos mencionado, la creación de la escritura. Existen esencialmente cuatro explicaciones mitológicas sobre el origen de esta última, que expondremos a continuación.

Es digno de mención que disponemos de fuentes textuales que recogen mitos ya desde la época de los 周 Zhōu del Este (entre los siglos VIII y III a.n.e.), pero, como indica Goepper, son discontinuas y poco sistemáticas. En las épocas posteriores se produjo un incremento de relatos míticos que hacían referencia a la antigüedad, sin embargo, estos no se basan en el descubrimiento de nuevas fuentes originales (textuales o arqueológicas), sino que corresponden a un esfuerzo de las corrientes de pensamiento por reforzar sus doctrinas, haciendo referencia a utópicas épocas antiguas (Goepper, 1988: 48).

Existen ciertos personajes que juegan un rol fundamental en la tradición mitológica china, son los llamados Tres Augustos (三皇 sān huáng) y Cinco Emperadores (五帝 wŭ di) legendarios. Los tres primeros son considerados comúnmente padres impulsores de la civilización china, los cinco siguientes gobernaron sociedades utópicas de una edad de oro.

Las fuentes textuales que hacen referencia a estos Tres Augustos y Cinco Emperadores son en ocasiones confusas y contradictorias, por lo que algunos de los personajes pueden variar según la fuente que se consulte (Zhang, 2013: 20).

La mitología sobre el origen de la escritura está estrechamente vinculada a la de cuatro personajes. Tres de ellos (Fúxī, Shénnóng y Huángdi) forman parte de los ya mencionados Tres Augustos y Cinco Em- 
peradores legendarios. Así, para tratar las explicaciones mitológicas de la escritura china hemos de hacer referencia a ellos. Fúxi es el primero de los Tres Augustos legendarios, Shénnóng es la divinidad de la agricultura y Huángdi el Emperador Amarillo; a estos hay que sumarles otro personaje llamado Cāngjié (ministro del Emperador Amarillo), no menos importante para nuestra exposición.

A pesar del carácter mítico de estos y otros personajes, cabe la posibilidad de que las leyendas provengan de personas reales que podrían haber sido idealizadas y mitificadas gracias a sus grandes hazañas en la antigüedad. Así pues, en cierto modo, en algunos casos la línea divisoria entre el mito y lo real es delgada y sutil, por eso, algunos autores prefieren designarlos como personajes semilegendarios.

\subsection{El mito de 伏羲 fúxī, el primero de los tres augustos legendarios}

Según el pensamiento taoísta tradicional chino recogido en el Libro de las mutaciones o 易经 Yì jīng (compilado durante la dinastía 周 Zhōu, por eso también llamado 周易 Zhōu Yì, y conocido usualmente en Occidente como I Ching), el mundo se rige por dos fuerzas dialécticamente opuestas 一阴 yìn y 阳 yáng-, que hacen que se encuentre en proceso de cambio constante. Dichas fuerzas, no solo son opuestas, son interdependientes, complementarias, y coexisten en armonía. El incremento máximo de cualquiera de ellas provoca su extinción, a la vez que origina y desarrolla la otra, y viceversa. De este modo, en el universo se van produciendo un sinfín de cambios cíclicos, por ejemplo: amanece, el sol se alza por el horizonte hasta que llega a su punto más alto, a partir de ahí comienza a descender, hasta que se pone y comienza a oscurecer, cae la noche y se hace cada vez más intensa hasta que, de nuevo, aparece el resplandor del sol por el horizonte, y así sucesivamente. Este principio se aplica a todo lo que existe en el Universo, así, según el Yĩ jīng la única realidad existente es el cambio.

Estas nociones son compartidas en Asia por distintas doctrinas de pensamiento. La idea de cambio como principio fundamental que rige la existencia está muy presente también en la tradición budista, donde es conocida como la "impermanencia". En el Libro tibetano de la vida y de la muerte se hace mención a un dicho popular en Tibet, según el cual es imposible lavar dos veces la misma mano sucia en el mismo río (Sogyal Rimpoché, 1992: 58). La doctrina budista también comparte la concepción de cambio constante y cíclico, según Rimpoché, la vida es una danza con- 
tinua entre nacimiento y muerte (Sogyal Rimpoché, 1992: 57), lo que, en realidad guarda una enorme analogía con la idea fundamental del Libro de las mutaciones.

En el Yì jīng se representa el principio yáng con una línea continua $(-)$, y el yīn con una discontinua (--), así de las combinaciones posibles entre ambos resultan los ocho trigramas (en China conocidos como 八卦 bāguà, son signos de tres líneas continuas o discontinuas, como se muestra en la parte inferior del gráfico que sigue), que se corresponden con fenómenos naturales y simbolizan los ocho estados de cambio fundamentales de la naturaleza.

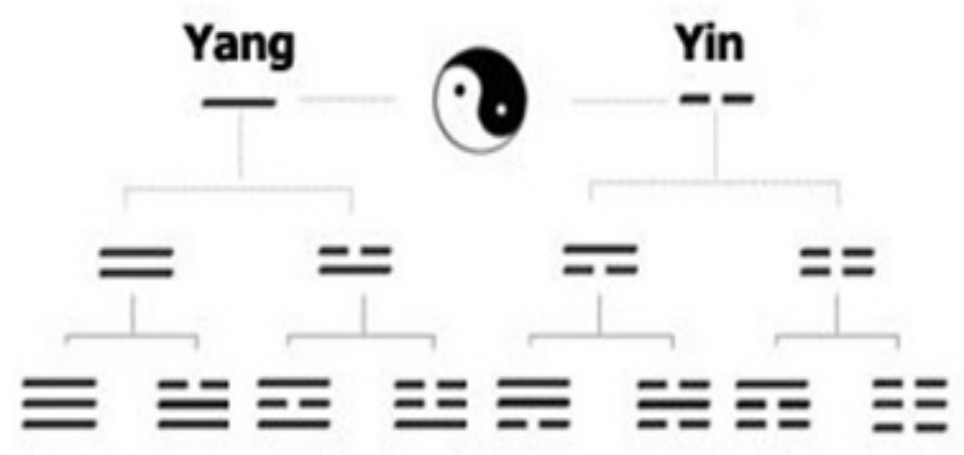

Uno de los mitos sobre el origen de la escritura china hace referencia a 伏羲 Fúxī, el primero de los Tres Augustos legendarios. Este se casó incestuosamente con su hermana la diosa 女娲 N constancia tanto a través de textos escritos, como de lápidas funerarias de la Dinastía Hàn (García-Noblejas, 2012: 88) y de la unión sexual entre ambos nacieron los seres humanos. Ambos suelen tener una representación zoomórfica, con cabeza y busto humanos y cuerpo de serpiente (véase: figura 1). Se supone que gobernó hace unos cinco milenios, durante unos 115 o 116 años aproximadamente. Según cuenta la leyenda enseñó varias artes a los hombres, observó la naturaleza e imitando a la araña creo la red para pescar y cazar (García Tapia, 2009: 320). A este emperador mitológico se le atribuye, entre otras cosas, la creación de los ocho trigramas y, por tanto, la mitología en torno a Fúxĩ versa no solo sobre la escritura, sino también sobre la cosmogonía, la filosofía y la medicina. Los estados de cambio representados con los trigramas explican el orden del universo, las 
leyes que lo rigen, los fenómenos de la naturaleza e incluso al ser humano. La correspondencia entre los trigramas y los elementos de la naturaleza es la siguiente: 三(乾 qián) cielo, 至(兑 duì) lago, 全(震 zhèn) trueno, 王 (離 lî)

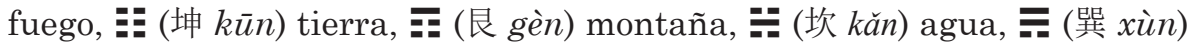
viento (Cleary, 1993: 21). Se considera que la analogía entre el signo gráfico de los trigramas y el elemento al que representa fue un precursor de la escritura. Por lo que, según esto, Fúxī es el creador de la escritura china.

Fúxī se cuenta entre los seres mitológicos que han pasado a recibir culto religioso en China. En la ciudad de 天水 Tiānshul̆, al norte del país, se encuentra uno de los templos en su honor (véase figura 2). Otros de los más emblemáticos están situados en 淮阳 Huáiyáng (provincia de 河南 Hénán) y en el poblado de 两城镇 Liăngchéng zhèn (junto a la ciudad de 日照 Rìzhào, provincia de 山东 Shāndōng).

Figura 1: imagen de estela funeraria del siglo II a.n.e. en donde están representados Fúxī y su esposa Nǚwā.

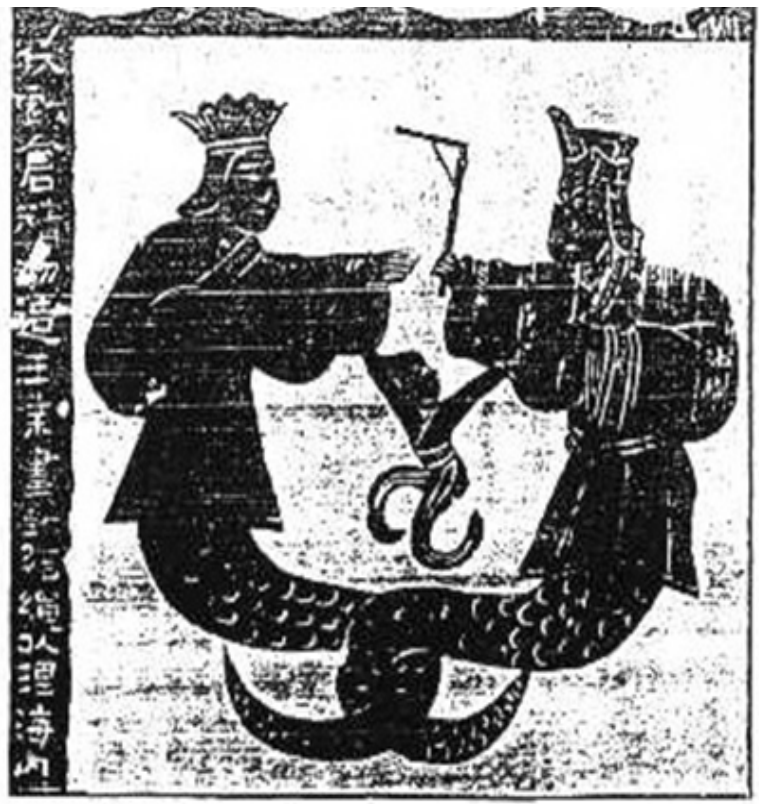

Fuente: https://es.wikipedia.org/wiki/Fuxi\#/media/Archivo:NuwaFuxi1.JPG

(Última revisión: 28/10/2019) 
Descripción: Fúxī con la escuadra (a la derecha), junto con la madre de la humanidad, Nǘwa (a la izquierda), con sus escamados cuerpos entrelazados, lo que parece simbolizar su unión sexual. Ambos representados zoomórficamente con cabeza y busto humanos y cuerpo de serpiente. Entre ellos un niño nacido de la unión de ambos, que representa a todos los seres humanos (García-Noblejas, 2007: 146-147). En otras ilustraciones encontramos a Nǚwā portando un compás (规 gū ) y a Fúxī una escuadra (

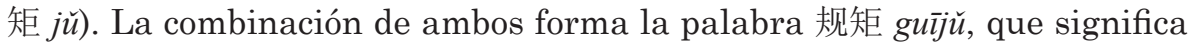
"normas, regulaciones", lo que simboliza que ellos son los creadores de las normas de la humanidad (Mu, 2012: 115).

Figura 2: Templo de Fúxī.

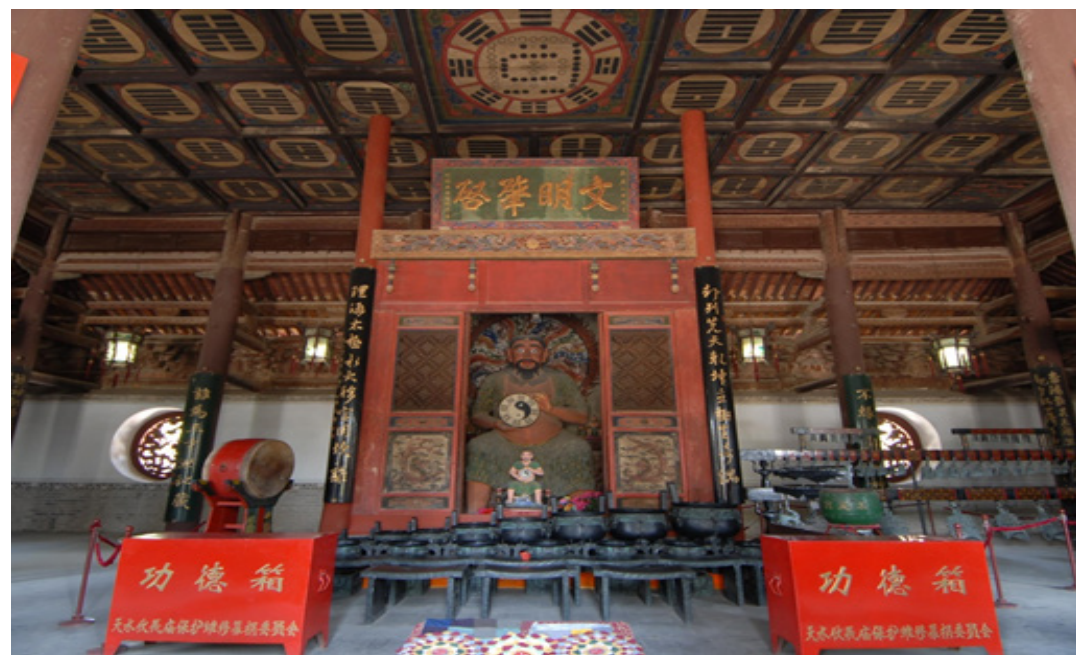

Fuente: https://www.mafengwo.cn/sales/2232844.html (Última revisión: 28/10/2019)

Descripción: templo erigido en la ciudad de 天水 Tiānshǔ̆, (provin-

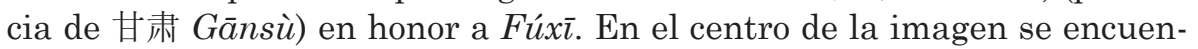
tran dos estatuas análogas del emperador legendario sujetando entre sus manos un bāguà con un yīnyáng en el centro. En el techo de la sala están 
representados los 64 hexagramas (derivados de las combinaciones de los 8 trigramas).

\subsection{El mito del labrador divino, 神农 shénnóng}

Shénnóng también se cuenta entre los Tres Augustos legendarios. De naturaleza divina, es considerado uno de los fundadores de la civilización china. Su mitología gira en torno a una utopía agraria. Se le atribuye la institución de mercados, pero en especial, la creación tanto de la agricultura, como de la medicina. Enseñó a los hombres el cultivo del sorgo e inventó el arado y la azada, y con ello ayudó a las personas a dejar el estado de salvajismo en que habían vivido hasta entonces, comiendo carne cruda y bebiendo sangre (Shaughnessy, 2008: 163). Según el mito, vio que muchas personas enfermaban por comer plantas tóxicas y, movido por el afán de ayudarlas, probó una inmensidad de hierbas, llegando a distinguir hasta setenta plantas venenosas al día. Descubrió no solo que había plantas perjudiciales para la salud, sino que otras servían para curar enfermedades y transmitió sus conocimientos a los seres humanos. También les enseñó la siembra de cereales y la distinción de las aguas puras y las contaminadas (García-Noblejas, 2007: 157-158). A él se le atribuye el Clásico de las raíces y las hierbas del Labrador Divino (本草经 Běn căo jīng), compilado en realidad durante la dinastía 汉 Hàn.

Además de esto, se le atribuye a Shénnóng la elaboración de un método tanto de contabilidad, como de registro de hechos, similar al quipu inca, que se llevaba a cabo mediante un sistema de cuerdas anudadas (Páez Gutiérrez, 2010: 28). Dicho sistema, conocido en China como 结绳 jiéshéng, también es considerado un posible precursor de la escritura, porque, en definitiva, su cometido no era sino dejar constancia de una cantidad o un hecho - para lo que se usaba un soporte duradero (las cuerdas)-, y, con ello, mantener vivo el recuerdo, lo que, al fin y al cabo, es la función de la escritura. 
Figura 3: representación tradicional de Shénnóng.

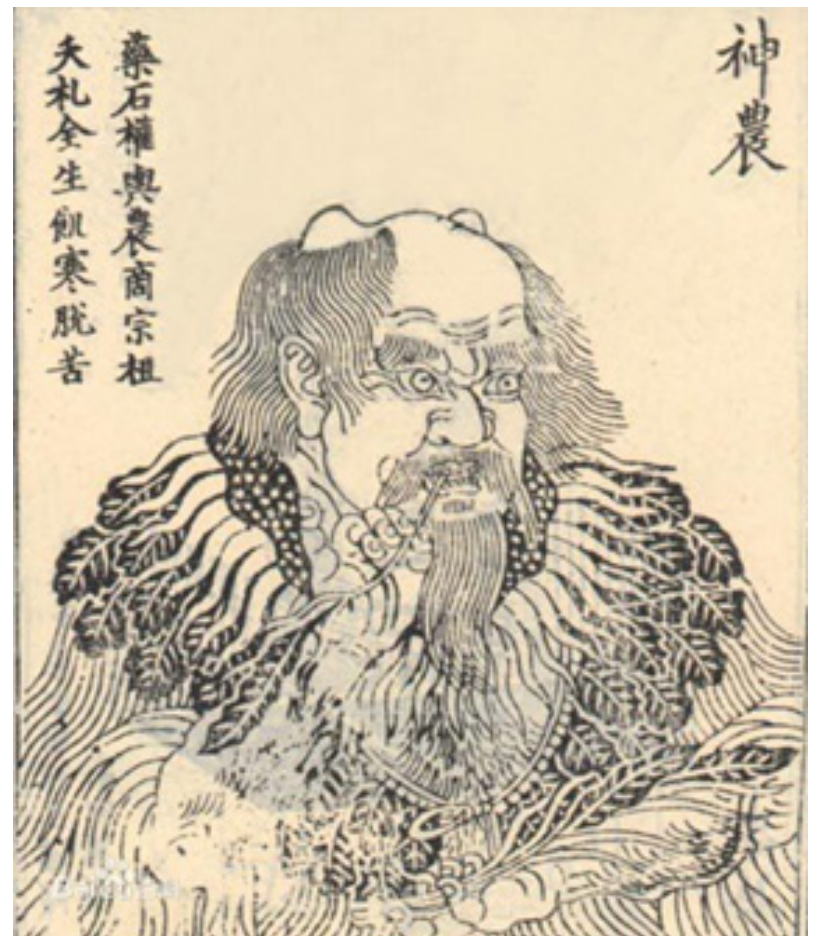

Fuente: https://rufodao.qq.com/a/20190528/002875.htm (Última revisión: 28/10/2019)

Descripción: Shénnóng como comúnmente se le suele representar: con cabeza corneada, probando hierbas y vistiendo prendas hechas de hojas de árboles o adornadas con ellas.

Durante veinte siglos se le han rendido en China cultos al Labrador Divino. Ya se hacían a comienzos de la dinastía Hàn (207 a.n.e.). Tenemos constancia de ellos gracias al Libro de la dinastía Han Posterior y Antiguos ritos de los Han. García-Noblejas nos proporciona descripciones detalladas de estos cultos que en esencia tenían un sentido agrícola. El rito principal, que era oficiado por el mismísimo emperador en persona, era 
conocido como «el primer surco» y de lo que se trataba, fundamentalmente, era de ganarse el favor del Labrador Divino para obtener una buena cosecha (García-Noblejas, 2007: 460-466).

Figura 4: estatua en honor a Shénnóng.

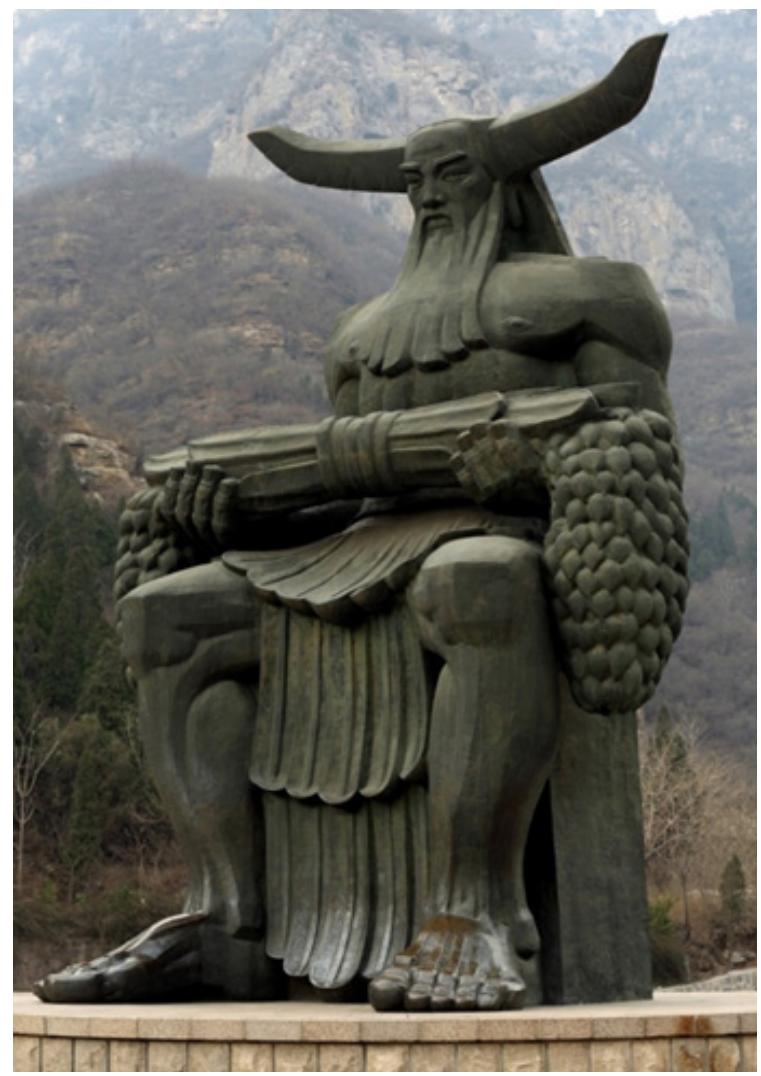

Fuente: http://blog.sina.com.cn/s/blog_49843fdb0102yea5.html (Última revisión: 28/10/2019)

Descripción: área turística en donde se encuentra una de las estatuas en honor al Labrador Divino, representado con una gran cornamenta. 
La estatua mide aproximadamente 9,9 metros de altura y pesa alrededor de 29 toneladas. Está situada en 神农山 Shénnóng shān, es decir, Montaña de Shénnóng, junto a la aldea de 赵寨村 Zhàozhài, en la provincia de 河南 Hénán, China.

\subsection{El mito del emperador amarillo, 黄帝 huángdi}

Otro de los grandes seres mitológicos del país es el Emperador Amarillo, quien según la tradición gobernó entre el 2698 y el 2598 a.n.e. aproximadamente. Se le considera uno de los padres de la raza y civilización chinas, pues según los mitos en torno a su persona se piensa que durante su gobierno se produjeron avances importantísimos -que hicieron posible el establecimiento del imperio en la llanura del 黄河 Huáng Hé o Río Amarillo-, tales como la fabricación de armas, la defensa de las tierras frente a los ataques de los pueblos bárbaros, la invención de la escritura, la música, la cerámica, los carros, las medicinas, las embarcaciones, los mapas, las casas de madera, el cultivo de la seda - puesto que la mitología china sobre la sericicultura hace referencia a cómo esta fue descubierta por su consorte, 嫘祖 Luózǔ, Diosa del Trueno, quien reveló a los chinos cómo cuidar los gusanos de seda alimentándolos con hojas frescas de morera- y la elaboración de uno de los textos fundamentales de la medicina tradicional china, el 黄帝内经 Huángdì Nèijīng o Canon interno del Emperador Amarillo.

También existe la versión de que los caracteres chinos le fueron dados al Emperador Amarillo como un don divino (Rovira Esteva, 2010: 27), no obstante, en la mayoría de referencias mitológicas sobre el tema, Huángdì participa en la creación de la escritura de forma indirecta, sin otro mérito que reinar cuando fue descubierta, puesto que los mitos se centran en otro personaje, Cāngjié, uno de sus oficiales. 
Figura 5: ilustración del Emperador Amarillo.

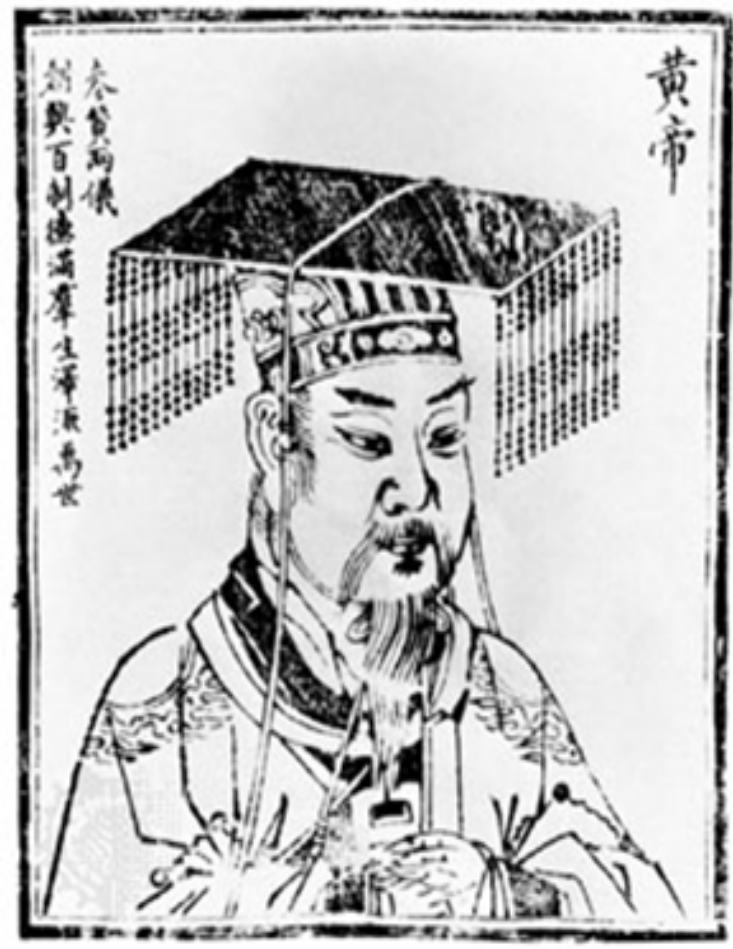

Fuente: https://www.britannica.com/topic/Huangdi

(Última revisión: 28/10/2019)

Descripción: ilustración del Emperador Amarillo, supuesto iniciador de la civilización y, como tal, considerado comúnmente padre o predecesor de todos los chinos. 
Figura 6: Mausoleo del Emperador Amarillo.

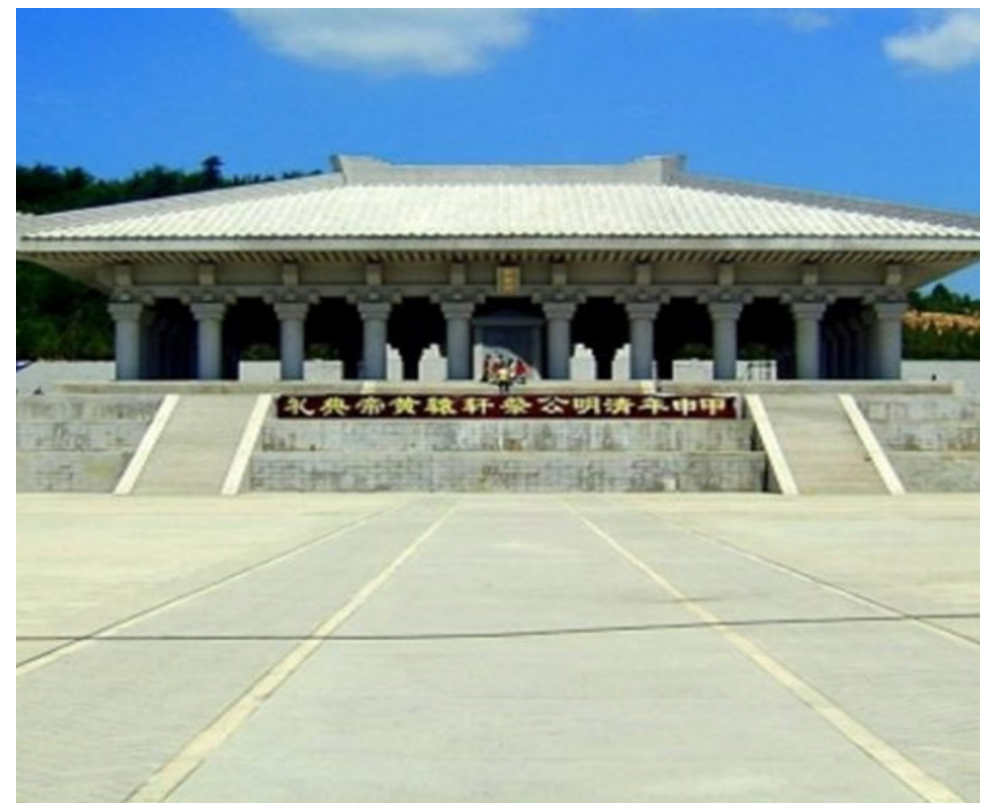

Fuente: http://www.bh2255.com/huangdiling-1347/ (Última revisión: 28/10/2019)

Descripción: Salón del Sacrificio, en chino 祭祀大殿 Jìsì Dàdiàn, edificación cuadrada de piedra de granito situada en la parte norte del mausoleo en honor a Huángdì, ubicado en la ciudad de 延安市 Yán'ān, en la provincia de 陕西 Shănxī, China. 


\subsection{El mito de 仓颕 cāngjié}

Existen numerosas alusiones que relacionan a Cāngjié con la invención de la escritura, han sido compiladas y tratadas con detalle por García-Noblejas. Las fuentes más antiguas datan del siglo III a.n.e. Se encuentran pasajes en obras como Libro del maestro Han Fei (siglo III a.n.e.), Libro del maestro Xun (siglo III a.n.e.), Anales del caballero Lü (239 a.n.e.), Libro del maestro Huainan (139 a.n.e.), Panorámica y egregios (entre 220-265 n.e.) y Recopilación general del Salón de la Literatura de la dinastía Han (textos de la dinastía Hàn, 206 a.n.e.-220 n.e., compilados durante la dinastía Ming, 1368 n.e.-1644 n.e.) (García-Noblejas, 2007: 147-155).

Las referencias a Cāngjié indican que este creó la escritura a través de la observación de la naturaleza, a saber: la forma de las constelaciones, los dibujos de los caparazones de tortugas, el trazado de las aguas por los montes, pero especialmente las huellas de los pájaros y cuadrúpedos. Parece que la asociación de las huellas con su animal correspondiente, le sirvió de inspiración para la creación de la escritura en su estadio primigenio, es decir, la asociación huella-animal lo condujo hasta la asociación pictografía-objeto real. 
Figura 7: ilustración de Cāngjié de la dinastía Qing (1644-1911 n.e.).

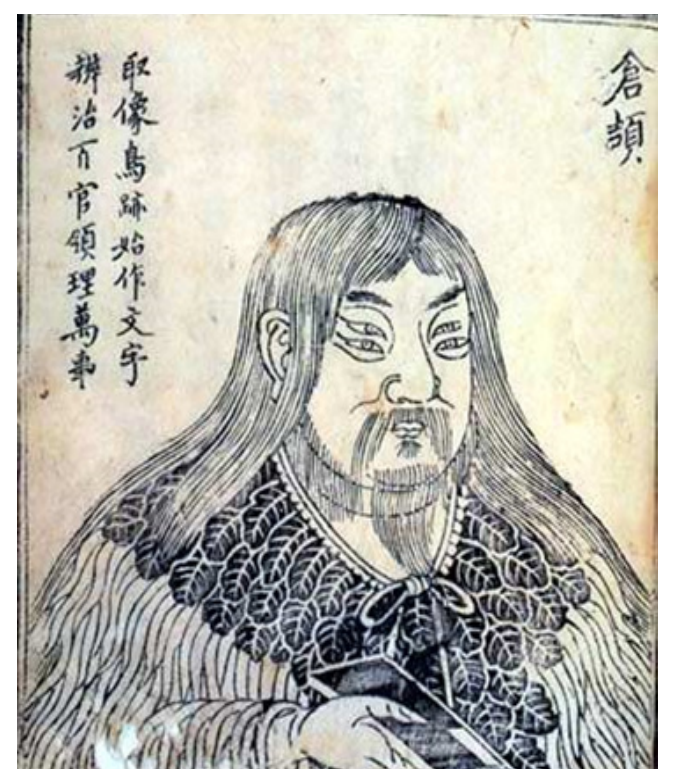

Fuente: http://rapidmandarin.com/wp-content/uploads/2014/10/ cang-jie.jpg

(Última revisión: 28/10/2019)

Descripción: los rasgos de Cāngjié se asemejan más a lo divino que a lo humano. Se suele representar con cuatro ojos y cuatro pupilas, además de ciertos rasgos zoomórficos, como son sus dedos alargados asemejados a garras, (hay fuentes que describen al personaje con una gran cabeza de dragón) y vestimentas decoradas con hojas de árbol. 


\section{Referencias bibliográficas}

Alleton, Viviane. (2009). La escritura china. Barcelona: Bellaterra.

Cheng, F. (2007). La escritura poética china: seguido de una antología de poemas de los Tang. Valencia: Pre-textos.

Cleary, Thomas. (1993). I Ching. Madrid: EDAF.

Folch Fornesa, María Dolors. (2002). La construcción de China: el período formativo de la civilización china. Barcelona: Península.

García Tapia, José Luis. (2009). Amarillo pasión. Hong Kong: O’Hagan and Dou Publishers HK Ltd.

García-Noblejas, Gabriel. (2007). Mitología de la China antigua. Madrid: Alianza Editorial.

García-Noblejas, Gabriel. (2012). La mitología. En Gabriel García-Noblejas (Ed.), China, pasado y presente de una gran civilización (pp. 75-92). Madrid: Alianza Editorial. nés Editores.

Goepper, Roger. (1988). La antigua China. Barcelona: Plaza \& Ja-

Martínez Robles, David. (2007). La lengua china: historia, signo y contexto: una aproximación sociocultural, 56. Barcelona: Editorial UOC.

$\mathrm{Mu}$, Yuhan. (2012). Genesis Stories from Chinese Mythology [中 国神话中的创世故事]. En Wang Lujiang 王路江 (Ed.), Lectures on Chinese Culture (II) (pp. 107-120). Beijing: Beijing language and culture university press.

Páez Gutiérrez, Tomás David. (2010). Las matemáticas a lo largo de la historia: de la prehistoria a la antigua Grecia. Madrid: Vision Libros.

Ramírez Bellerín, Laureano. (2004): Manual de traducción chino/ castellano. Barcelona: Gedisa.

Rovira Esteva, Sara. (2010). Lengua y escritura chinas: Mitos y realidades. Barcelona: Edicions Bellaterra.

Shaughnessy, Edward L. (2008). China. Barcelona: BLUME.

Sogyal Rimpoché. (1992). El libro tibetano de la vida y de la muerte. Barcelona: Urano.

Spence, Lewis. (2000). Introducción a la mitología. Madrid: Edimat libros. 
Zhang, Peng. y Ni, Maohua. (2013). Cultura china [中国文化]. Shanghai: Shanghai foreign language education press. 